\title{
Yttria Promoted Nickel Nanowire Catalyst for the Partial Oxidation of Methane to Synthesis Gas
}

\author{
Xuebin Hong, Bingbing Li, Cong Zhang \\ Renai College of Tianjin University, Tianjin 301636, P. R. of China \\ Email: hong_xuebin@yahoo.com.cn
}

Received 2012

\begin{abstract}
A yttria promoted nickel nanowire catalyst was prepared by a hard templating method, and characterized by transmission electron microscopy (TEM) and $\mathrm{N}_{2}$ physical adsorption. The catalytic properties of the yttria promoted nanowire catalyst in the partial oxidation of methane to syngas were compared with a metallic Ni catalyst which was prepared with nickel sponge. The characterization results showed that the yttria promoted nickel nanowire catalyst had high specific surface area and there was more NiO phase in the nickel nanowire catalyst than in the metallic Ni catalyst. The reaction results showed that the yttria promoted nickel nanowire catalyst had high $\mathrm{CH}_{4}$ conversion and selectivities to $\mathrm{H}_{2}$ and $\mathrm{CO}$.
\end{abstract}

Keywords: Yttria; Nanowire; Methane; Partial Oxidation; Syngas

\section{Introduction}

The conversion of natural gas into liquid fuels is commonly performed via an indirect route through synthesis gas, a mixture of $\mathrm{H}_{2}$ and $\mathrm{CO}$ [1-3]. Industrially, synthesis gas is mainly produced from methane steam reforming process [4-6]. Such a process produces a high $\mathrm{H}_{2} / \mathrm{CO}$ ratio [7]. Furthermore, methane steam reforming is highly endothermic and heat-transfer limited [8]. Catalytic partial oxidation of methane (CPOM) is an attractive alternative for the syngas production [9-12] as the reaction is mildly exothermic and a $\mathrm{H}_{2} / \mathrm{CO}$ ratio of 2 can be achieved, which is desirable for Fischer-Tropsch synthesis [13-15], methanol synthesis, etc.

The first row of transition metals (Ni, Co) and precious metals ( $\mathrm{Ru}, \mathrm{Rh}, \mathrm{Pd}, \mathrm{Pt}$, and $\mathrm{Ir}$ ) have been reported as active catalysts for CPOM $[16,17]$. Among these, Ni has been intensively studied. Recently, the synthesis of nickel oxide with controlled nanostructures, such as mesoporous solids, nanotubes or nanowires, has attracted considerable attention because such material may exhibit better catalytic properties and be more readily available [18-23]. Kim et al [24] synthesized a mesoporous Ni-Alumina catalyst and compared the performance with a nickel catalyst impregnated on a commercially available alumina support (Ni-IMP) in CPOM. They found that the Ni-Alumina catalyst showed a relatively high surface area with a narrow pore size distribution. And the Ni-Alumina catalyst having smaller nickel particles and lower levels of carbon deposition had a more stable catalytic activity than the Ni-IMP catalyst.

The reaction of CPOM over a metallic Ni catalyst prepared with nickel sponge has been studied [25]. The results showed that the metallic Ni catalyst has some advantages over the supported nickel or nickel coated catalysts. For example, in the supported nickel or nickel coated catalysts, the fine nickel particles tend to aggregate at high temperatures and lose the activity $[26,27]$. However, in the metallic Ni catalyst, the nickel acts as both active component and the support, so it would not ag- gregate further [25].

In this work, we prepared a yttria promoted nickel nanowire catalyst by a hard templating method. The catalyst consists of nickel nanowires, which has higher specific surface area than the one prepared with nickel sponge. It is expected that the yttria promoted nickel nanowire catalyst should have higher activity for CPOM, while keeping the advantages of the metallic nickel catalyst.

\section{Experimental}

\subsection{Catalyst Preparation}

Three-dimensional mesoporous silica (KIT-6) was synthesized according to references [28-31], and used as the hard template for the preparation of yttria promoted nickel nanowires. For the preparation of the yttria promoted nickel nanowires, $1.5 \mathrm{~g}$ of $\mathrm{Ni}\left(\mathrm{NO}_{3}\right)_{2} .6 \mathrm{H}_{2} \mathrm{O}(98.0 \%)$ and $1.0 \mathrm{~g} \mathrm{Y}\left(\mathrm{NO}_{3}\right)_{3}$ were dissolved in $1.0 \mathrm{~cm}^{3}$ distilled water forming a saturated solution, followed by addition of $2.0 \mathrm{~g}$ of KIT-6, which resulted an incipient impregnation. After drying at $373 \mathrm{~K}$ until all the water had been vaporized and a dry powder obtained, the sample was heated slowly to $823 \mathrm{~K}$ in air and calcined in a muffle furnace at that temperature for $5 \mathrm{~h}$. Then, in the presence of hydrogen, the sample was heated at $1 \mathrm{~K} / \mathrm{min}$ from ambient temperature to $1123 \mathrm{~K}$, kept at the final temperature for $2 \mathrm{~h}$, and then cooled down to ambient temperature. The above process was repeated for four times. Then, the resulting sample was twice treated with a hot $4.0 \mathrm{~mol} / \mathrm{L} \mathrm{NaOH}$ solution to remove the silica template, followed by washing with distilled water and ethanol several times, and then drying at room temperature. The sample was triturated into 40-60 mesh.

The preparation of the metallic $\mathrm{Ni}$ catalyst has been described before [25]. Briefly, a piece of metallic Ni sponge (80 \% porosity, Changsha Liyuan Material Co., Ltd.) was cut into 40-60 mesh, treated with a mixture of $500 \mathrm{~cm}^{3}$ containing 
0.01 wt. \% $\mathrm{HCl}$ and 0.2 wt. \% $\mathrm{H}_{2} \mathrm{SO}_{4}$ for $24 \mathrm{~h}$, and then thoroughly washed with distilled water and dried. This pretreatment results in the formation of $0.18 \sim 0.92 \mu \mathrm{m}$ wide channels across the surface [25].

\subsection{Catalyst Characterization}

Transmission electron microscopy (TEM) investigations were carried out using a FEI Tecnai G2 F20 apparatus, operated at an accelerating voltage of $200 \mathrm{kV}$. The sample powders were dispersed in ethanol by ultrasonic radiation and the solution was dropped on the sample holder, which is a copper grid coated with a carbon film.

The specific surface areas of the samples were determined by nitrogen physical adsorption at liquid nitrogen temperature using a Mike TriStar 3000 instrument. All samples were degassed at $573 \mathrm{~K}$ for $5 \mathrm{~h}$ prior to analysis. The specific surface areas were calculated according to the method of Brunauer, Emmett and Teller (BET).

\subsection{Experimental Procedures}

CPOM was studied with a quartz reactor with $10 \mathrm{~mm}$ internal diameter, which was heated by an electric furnace. The catalyst temperature was measured by a chromel-alumel thermocouple which was inserted into a quartz thermocouple well, with the thermocouple tip being placed in the middle of the catalyst bed. In a typical run, the catalyst (diluted with double portions of quartz silica of the same size as the catalyst), with the total volume of $0.39 \mathrm{~cm}^{3}$, was packed in the reactor with a layer of silica wool below. The reactant gases of $\mathrm{CH}_{4}(99.8 \%)$ and $\mathrm{O}_{2}$ (99.9\%), controlled by mass flow controllers, were passed through the reactor and the temperature was increased to the required value with the electric furnace.

Reaction products were analyzed by a 3420 Gas Chromatograph equipped with a TCD detector and two columns, a 5A molecular sieve column for the separation of $\mathrm{O}_{2}, \mathrm{CH}_{4}$ and $\mathrm{CO}$, and a carbon molecular sieve column for the separation of $\mathrm{H} 2$ and $\mathrm{CO}_{2}$. Quantification was performed by injecting a gas mixture with known compositions for the calibration.

The equations for the calculation of the conversion of $\mathrm{CH}_{4}$, $\mathrm{CON}_{\mathrm{CH} 4}$, and the selectivities to $\mathrm{H}_{2}$ and $\mathrm{CO}, \mathrm{S}_{\mathrm{H} 2}$ and $\mathrm{S}_{\mathrm{CO}}$, are given as follows:

$$
\begin{gathered}
\mathrm{CON}_{\mathrm{CH} 4}=\left(\mathrm{F}_{\mathrm{CO} \text {,outlet }}+\mathrm{F}_{\mathrm{CO} 2 \text {,outlet }}\right) /\left(\mathrm{F}_{\mathrm{CO} \text {,outlet }}+\mathrm{FCO} 2\right. \text {,outlet } \\
\left.+\mathrm{F}_{\mathrm{CH} 4 \text {,outlet }}\right) \times 100 \% \\
\mathrm{~S}_{\mathrm{H} 2}=\mathrm{F}_{\mathrm{H} 2 \text {,outlet }} /\left(2 \times\left(\mathrm{F}_{\mathrm{CO} \text {,outlet }}+\mathrm{F}_{\mathrm{CO} 2 \text {,outlet }}\right)\right) \times 100 \% \\
\mathrm{~S}_{\mathrm{CO}}=\mathrm{F}_{\mathrm{CO} \text {,outlet }} /\left(\mathrm{F}_{\mathrm{CO} \text {,outlet }}+\mathrm{F}_{\mathrm{CO} 2 \text {,outlet }}\right) \times 100 \%
\end{gathered}
$$

where $F_{x}$ is the mole number of substance $x$. No oxygen breakthrough was found in the CPOM reaction.

\section{Results and Discussion}

\subsection{Characterization of Catalysts}

Morphology of the yttria promoted nickel nanowire catalyst was determined by TEM and is shown in Figure 1. It is seen that the catalyst consists of nanowires. The nanowires are stacked together, probably because that they are paramagnetic and cannot be dispersed by ultrasonic radiation. But the nanowires are not structurally connected. By measuring at high magnification, the diameter of the nickel nanowires was measured to be approximately $8 \mathrm{~nm}$.

The specific surface area of the yttria promoted nickel nanowire catalyst $\left(9.77 \mathrm{~m}^{2} / \mathrm{g}\right)$ is much higher than that of the metallic Ni catalyst $\left(0.25 \mathrm{~m}^{2} / \mathrm{g}\right)$.

\subsection{Results of the Reaction of CPOM}

Changes of methane conversions and $\mathrm{H}_{2}$ and $\mathrm{CO}$ selectivities on the yttria promoted nickel nanowire catalyst and the metallic $\mathrm{Ni}$ catalyst with $\mathrm{CH}_{4} / \mathrm{O}_{2}$ ratios, reaction temperature, and GHSV are shown in Figures 2 to 4, respectively. It can be seen that with the increase of $\mathrm{CH}_{4} / \mathrm{O}_{2}$ ratios, the methane conversions on both catalysts decrease and the selectivities to synthesis gas increase (Figure 2). With the increase of the reaction temperature, the methane conversions and the selectivities to $\mathrm{H}_{2}$ and $\mathrm{CO}$ on both catalysts also increase (Figure 3). With the increase of GHSV, the $\mathrm{CH}_{4}$ conversion and $\mathrm{H}_{2}$ and $\mathrm{CO}$ selectivities on the metallic $\mathrm{Ni}$ catalyst increase, but those on the yttria promoted nickel nanowire catalyst decrease (Figure 4). These tendencies were agreed with the perspectives of what are already known in literatures [32-38], except the changes of the $\mathrm{CH}_{4}$ conversion and the selectivities to syngas on the yttria promoted nickel nanowire catalyst with the increase of GHSV. This will be explained below.
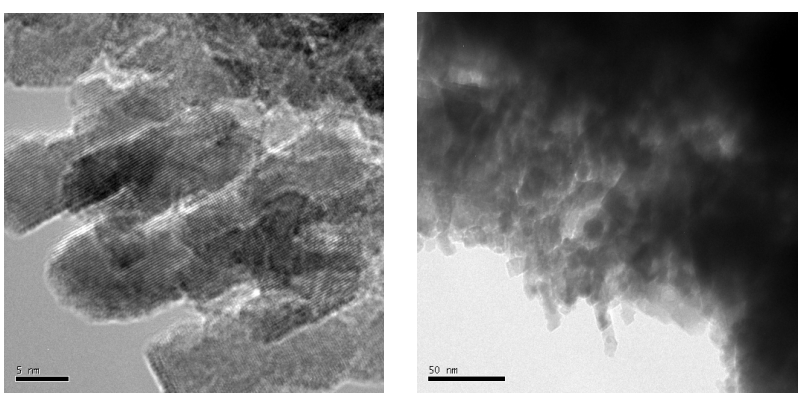

Figure 1. TEM images of the yttria promoted nickel nanowire catalyst at different magnifications, $5 \mathrm{~nm} ; 50 \mathrm{~nm}$.

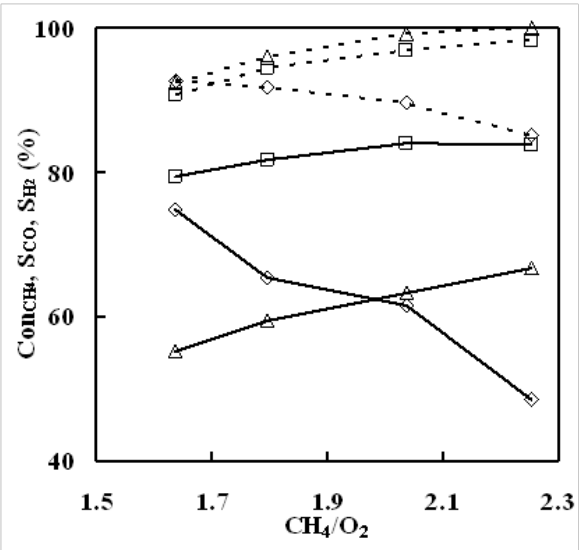

Figure 2. Comparison of $\mathrm{CH}_{4}$ conversions and $\mathrm{H}_{2}$ and $\mathrm{CO}$ selectivities between metallic $\mathrm{Ni}$ catalyst (solid lines) and the yttria promoted nickel nanowire catalyst (dashed lines) at different $\mathrm{CH}_{4} / \mathrm{O}_{2}$ ratios, $(\diamond)$ methane conversion; $(\Delta) \mathrm{H}_{2}$ selectivity; ( $\square$ ) CO selectivity. Reaction conditions: Temperature $=1123 \mathrm{~K}, \mathrm{GHSV}=2.0 \times 10^{4} \mathrm{~h}^{-1}$. 


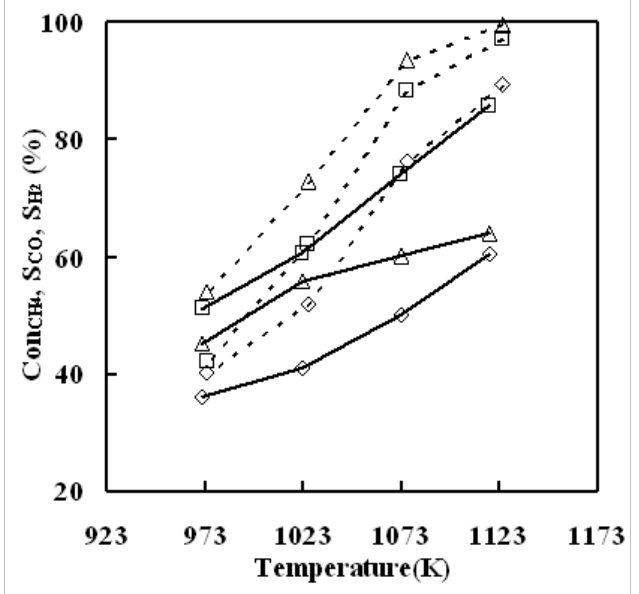

Figure 3. Comparison of $\mathrm{CH}_{4}$ conversions and $\mathrm{H}_{2}$ and $\mathrm{CO}$ selectivities between metallic $\mathrm{Ni}$ catalyst (solid lines) and the yttria promoted nickel nanowire catalyst (dashed lines) at different reaction temperatures, $(\diamond)$ methane conversion; $(\Delta) \mathrm{H}_{2}$ selectivity; ( $($ ) $\mathrm{CO}$ selectivity. Reaction conditions: $\mathrm{CH}_{4} / \mathrm{O}_{2}=2.0, \mathrm{GHSV}=2.0 \times 10^{4} \mathrm{~h}^{-1}$.

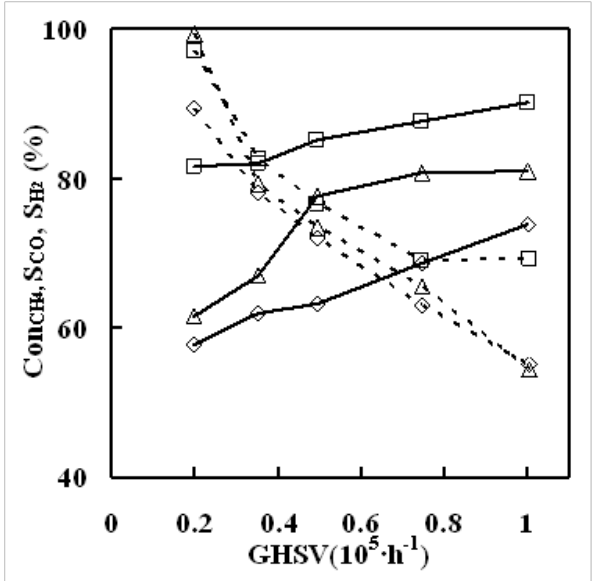

Figure 4. Comparison of $\mathrm{CH}_{4}$ conversions and $\mathrm{H}_{2}$ and $\mathrm{CO}$ selectivities between metallic Ni catalyst (solid lines) and the yttria promoted nickel nanowire catalyst (dashed lines) at different GHSV, $(\diamond)$ methane conversion; $(\Delta) \mathrm{H}_{2}$ selectivity; ( $\square$ ) CO selectivity. Reaction conditions: Temperature $=1123 \mathrm{~K}, \mathrm{CH}_{4} / \mathrm{O}_{2}=2.0$.

However, it is noted that on the yttria promoted nickel nanowire catalyst, the methane conversion and the selectivities to $\mathrm{H}_{2}$ and $\mathrm{CO}$ are much higher than those on the metallic Ni catalyst under the same reaction conditions. For example, as shown in Figure 2, on the yttria promoted nickel nanowire catalyst, at reaction temperature $1123 \mathrm{~K}$, GHSV $2.0 \times 10^{4} \mathrm{~h}^{-1}$, and $\mathrm{CH}_{4} / \mathrm{O}_{2}$ ratio 2.0, the conversion of methane and the selectivities to hydrogen and carbon monoxide are $90 \%$, $99 \%$, and $97 \%$, respectively, much higher than those on the metallic Ni catalyst, which are $58 \%, 62 \%$, and $82 \%$, respectively. The value of the conversion on the yttria promoted nickel nanowire catalyst is a little lower than the thermodynamic equilibrium value, which is $95 \%$, but the values of the selectivities to syngas are near to the thermodynamic equilibrium values, which are $98 \%$ and $98 \%$, respectively.
In general, it is known that defects, such as oxygen vacancies, are important in the surface chemistry and catalysis of metal oxides [39]. And the improved catalytic performance in oxidation catalysis has been attributed to a high concentration of oxygen vacancies [40-43]. Lattice oxygen ions often involve in reactions over oxide catalysts. Most of the partial oxidation reactions proceed via the Mars-van Krevelen mechanism, which is a redox model [44-47]. In this model, hydrocarbons react with surface lattice oxygen ions to form oxidized products, leaving a series of oxygen vacancies which are pending to be recruited by new formed lattice oxygen ions. The cycle for catalytic partial oxidation is closed via replenishment of the extracted lattice oxygen ions through the dissociative adsorption of molecular oxygen on the surface [48].

In the present work, the yttria promoted nickel nanowire catalyst had higher activity and selectivity. We infer that the reaction might proceed through the Mars-van Krevelen mechanism. The yttria promoted nickel nanowire catalyst had higher specific surface area, which shows promotion effect on the activity of catalyst, because the activity of catalyst was directly related to its surface area [49]. Higher surface area results in higher activity. Therefore, methane conversion and the selectivities to syngas on the yttria promoted nickel nanowire catalyst were much higher than those on the metallic Ni catalyst under the same reaction conditions.

From the reaction results (Figure 4), it is seen that the conversion and the selectivities on the yttria promoted nickel nanowire catalyst decreased with the increase of GHSV, while those on the metallic Ni catalyst increased. The difference in convective heat transfer coefficients for the two catalysts might be the most important reason to explain the differences in catalytic results. When heat was removed from the surface faster than it was generated by reaction, the temperature would fall. When the temperature fell below the ignition temperature of methane oxidation, reaction no longer occurred on that portion of the catalyst. This behavior was known as blowout. Blowout would occur easier on a catalyst geometry that had a high convective heat transfer coefficient [50]. Convective heat transfer occurs axially in the direction of flow, acting to transfer heat from the surface to the cooler gases. The convective heat transfer was much more efficient at removing heat from the yttria promoted nickel nanowire catalyst because of the much higher surface area and the tortuous flow passages in the catalyst [51]. With the increase of GHSV, the reactants increased in the feed which could result in the reaction blowout on the yttria promoted nickel nanowire catalyst. This led to the decrease in methane conversion and the selectivities to syngas on the yttria promoted nickel nanowire catalyst with the increase of GHSV.

\section{Conclusions}

The yttria promoted nickel nanowire catalyst has higher BET surface area than the metallic Ni catalyst. There is more NiO phase in the yttria promoted nickel nanowire catalyst than in the metallic Ni catalyst, which brings on more active centers in the CPOM.

The yttria promoted nickel nanowire catalyst had higher $\mathrm{CH}_{4}$ conversion and $\mathrm{H}_{2}$ and $\mathrm{CO}$ selectivities than the metallic $\mathrm{Ni}$ during CPOM. With the increase of $\mathrm{CH}_{4} / \mathrm{O}_{2}$ ratios, the methane 
conversions on both catalysts decrease and the selectivities to syngas increase. With the increase of the reaction temperature, the methane conversions and the selectivities to $\mathrm{H}_{2}$ and $\mathrm{CO}$ on both catalysts increase. With the increase of GHSV, the methane conversion and $\mathrm{H}_{2}$ and $\mathrm{CO}$ selectivities on the metallic $\mathrm{Ni}$ catalyst increase, but those on the yttria promoted nickel nanowire catalyst decrease.

\section{REFERENCES}

[1] R.C. Ramaswamy, P.A. Ramachandran, M.P. Dudukovic, Ind. Eng. Chem. Res. 46, 8638 (2007).

[2] C.J. Bell, C.A. Leclerc, Energy Fuels 21, 3548 (2007).

[3] M. Fleys, W.J. Shan, Y. Simon, P.M. Marquaire, Ind. Eng. Chem. Res. 46, 1063 (2007).

[4] C.W. Hu, J.J. Wu, H.L. Zhang, S. Qin, AIChE J. 53, 2925 (2007).

[5] T.V. Choudhary, V.R. Choudhary, Angew. Chem. Int. Ed. 47, 2 (2008).

[6] K.A. Williams, R. Horn, L.D. Schmidt, AIChE J. 53, 2097 (2007).

[7] J.H. Ryu, K.Y. Lee, H.J. Kim, J.I. Yang, H. Jung, Appl. Catal., B: Environ. 80, 306 (2008).

[8] U. Balachandran, J.T. Dusek, P.S. Maiya, B. Ma, R.L. Mieville, M.S. Kleefisch, C.A. Udovich, Catal. Today 36, 265 (1997).

[9] V.R. Choudhary, A.M. Rajput, B. Prabhakar, J. Catal. 139, 326 (1993).

[10] S.J. Feng, S. Ran, D.C. Zhu, W. Liu, C.S. Chen, Energy Fuels 18, 385 (2004).

[11] V.R. Choudhary, K.C. Mondal, T.V. Choudhary, Catal. Commun. 8, 561 (2007).

[12] T.F. Liu, C. Snyder, G. Veser, Ind. Eng. Chem. Res. 46, 9045 (2007).

[13] Z.X. Wang, T. Dong, L.X. Yuan, T. Kan, X.F. Zhu, Y. Torimoto, M. Sadakata, Q.X. Li, Energy Fuels 21, 2421 (2007).

[14] P. Mukoma, D. Hildebrandt, D. Glasser, N. Coville, Ind. Eng. Chem. Res. 46, 156 (2007)

[15] A.B. Mhadeshwar, D.G. Vlachos, Ind. Eng. Chem. Res. 46, 5310 (2007).

[16] S.F. Rice, A.H. McDaniel, E.S. Hecht, A.J.J. Hardy, Ind. Eng. Chem. Res. 46, 1114 (2007).

[17] J.H. Ryu, K.Y. Lee, H. La, H.J. Kim, J. Yang, H. Jung: J. Power Sources, Available online 23 June 2007.

[18] H.J. Wan, X.J. Li, S.F. Ji, B.Y. Huang, K. Wang, C.Y. Li, J. Nat. Gas Chem. 16, 139 (2007).

[19] M. Rezaei, S.M. Alavi, S. Sahebdelfar, P. Bai, X.M. Liu, Z.F. Yan, Appl. Catal., B: Environ. 77, 346 (2008).

[20] Y.Q. Song, D.H. He, B.Q. Xu, Appl. Catal., A: Gen. Available online 29 November 2007.

[21] J.T. Hu, T.W. Odom, C.M. Lieber: Acc. Chem. Res., 32, 435 (1999).
[22] A. Taguchi, F. Schuth: Micropor. Mesopor. Mater., 77, 1 (2005).

[23] C.C. Wang, J.Y. Ying: Chem. Mater., 11, 3113 (1999).

[24] P. Kim, Y.H. Kim, H.S. Kim, I.K. Song, J.H. Yi: Appl. Catal., A, 272, 157 (2004).

[25] Y.H. Li, Y.Q. Wang, X.B. Hong, Z.G. Zhang, Z.P. Fang, Y. Pan, Y.B. Lu, Z.Q. Han: AIChE J., 52, 4276 (2006).

[26] D.J. Mei, Y.Q. Chen, J.B. Zhong, Z.L. Wei, D. Ma, M.C. Gong: J. Rare Earth, 25, 311 (2007).

[27] P.M. Torniainen, X. Chu, L.D. Schmidt: J. Catal., 146, 1 (1994).

[28] F. Kleitz, S.H. Choi, R. Ryoo: Chem. Commun., 17, 2136 (2003).

[29] T.W. Kim, F. Kleitz, B. Paul, R. Ryoo: J. Am. Chem. Soc., 127, 7601 (2005).

[30] T.W. Kang, Y.G. Park, J.H. Yi: J. Mol. Catal. A, 244, 151 (2006).

[31] M.K. Dongare, K. Malshe, C.S. Gopinath, I.K. Murwani, E. Kemnitz: J. Catal., 222, 80 (2004).

[32] H. Mori, C.J. Wen, J. Otomo, K. Eguchi, H. Takahashi: Appl. Catal. A, 245, 79 (2003).

[33] S. Eriksson, S. Rojas, M. Boutonnet, J.L.G. Fierro: Appl. Catal., A, 326, 8 (2007).

[34] C.T. Au, M.S. Liao, C.F. Ng: J. Phys. Chem. A, 102, 3959 (1998).

[35] Y. Boucouvalas, Z.L. Zhang, X.E. Verykios: Catal. Lett., 40, 189 (1996).

[36] S. Rabe, T.B. Truong, F. Vogel: Appl. Catal. A, 318, 54 (2007).

[37] L. Chen, Q. Hong, J. Lin, F.M. Dautzenberg: J. Power Sources, 164, 803 (2007).

[38] A.S. Bodke, S.S. Bharadwaj, L.D. Schmidt: J. Catal., 179, 138 (1998).

[39] D.A. Hickman, L.D. Schmidt: AIChE J., 39, 1164 (1993).

[40] M. Labaki, S. Siffert, J.F. Lamonier, E.A. Zhilinskaya, A. Aboukais: Appl. Catal., B, 43, 261 (2003).

[41] J.J. Zhu, S. Albertsma, J.G. van Ommen, L. Lefferts: J. Phys. Chem. B, 109, 9550 (2005).

[42] Li, C. Y.; Shen, Y. N.; Jia, M. L.; Sheng, S. S.; Adebajo, M. O.; Zhu, H. Y. Catal. Commun. 9, 355 (2008).

[43] Durme, J. V.; Dewulf, J.; Leys, C.; Langenhove, H. V. Appl. Catal., B: Environ. 74, 324 (2008).

[44] W.X. Kuang, Y. Fan, Y. Chen: Langmuir, 16, 1440 (2000).

[45] Z.X. Liu, Q.X. Bao, N.J. Wu: J. Catal., 113, 45 (1988).

[46] Galvez, M. E.; Boyano, A.; Lazaro, M. J.; Moliner, R. Chem. Eng. J. Available online 12 January 2008.

[47] Baylet, A.; Royer, S.; Marecot, P.; Tatibouet, J. M.; Duprez, D. Appl. Catal., B: Environ. 77, 237 (2008).

[48] J.J. Zhu, J.G. van Ommen, H.J.M. Bouwmeester, L. Lefferts: J. Catal., 233, 434 (2005).

[49] S. Ozkar, M. Zahmakiran: J. Alloys. Compd., 404, 728 (2005).

[50] K.L. Hohna, L.D. Schmidt: Appl. Catal., A, 211, 53 (2001).

[51] S. Whitaker: AIChE J., 18, 361 (1972). 